\title{
Administration of Ginkgo biloba Extract (EGb761) Alone and in Combination with FK506 Promotes Liver Regeneration in a Rat Model of Partial Hepatectomy
}

\author{
Nahide Ekici Günay1, Sabahattin Muhtaroğlu², Abdulkadir Bedirli3 \\ ${ }^{1}$ Department of Clinical Biochemistry, University of Health Sciences, Training and Research Hospital, Kayseri, Turkey \\ ${ }^{2}$ Department of Clinical Biochemistry, Erciyes University School of Medicine, Kayseri, Turkey \\ ${ }^{3}$ Department of General Surgery, Gazi University School of Medicine, Ankara, Turkey
}

\begin{abstract}
Background: Free radical damage is known to occur during liver regeneration. The Ginkgo biloba extract EGb761 has antioxidant properties due to its ability to scavenge free radicals. FK506 has been widely used as an immunosuppressant that stimulates hepatocyte proliferation following partial hepatectomy.

Aims: To explore whether EGb761 enhances liver regeneration after hepatectomy in rats, we investigated the effects of EGb761 alone and in combination with FK506 on the liver regenerative process.

Study Design: Animal experimentation.

Methods: A total of 75 Wistar albino rats weighing $340.08 \pm 11.66$ $\mathrm{g}$ were randomly divided into five experimental groups: sham, control, FK506, EGb761, and FK506 + EGb761. According to the study groups, rats were administered FK506 at a dose of $0.1 \mathrm{mg} / \mathrm{kg} /$ day and EGb761 at $25 \mathrm{mg} / \mathrm{kg} /$ day three times via the intraperitoneal route. Then, two-thirds hepatectomy was performed according to the Higgins and Anderson technique in all the rats. At postoperative 48 h, 53 surviving rats were sacrificed. Serum and plasma samples were collected for analyzing thymidine kinase and oxidative stress marker levels. The regenerated liver was entirely resected, weighed, and
\end{abstract}

sectioned. The mitotic index was assessed using hematoxylin-eosin staining. The extent of liver regeneration was calculated using the Child's formula. The data were statistically analyzed using ANOVA, with a significance level of $5 \%(\mathrm{p}<0.05)$.

Results: Rats who received EGb761 showed significantly higher levels of liver regeneration than those who received FK506 or FK506 + EGb761 $(\mathrm{p}<0.01)$. Thymidine kinase level and mitotic index were significantly higher in the EGb761 ( $<<0.005)$ and FK506 ( $<<0.05)$ groups than in the control and sham groups. In addition, the liver regeneration percentage was significantly higher in the EGb761 group than in the FK506 group $(\mathrm{p}<0.01)$. Myeloperoxidase and malondialdehyde levels were significantly correlated between the EGb761 and FK506 groups, even at lower levels in the EGb761 group ( $\mathrm{p}<0.001)$.

Conclusion: EGb761, which is an antioxidant, reduces liver damage and stimulates liver regeneration following partial hepatectomy in rats through its anti-inflammatory and antioxidative effects.

Keywords: EGb761, FK506, hepatectomy, liver, oxidative stress, regeneration, thymidine kinase, mitosis
Liver regeneration following partial hepatectomy is regulated by the immune system (1). In the early phase of liver regeneration, free radical damage is known to occur; lipid peroxidation has been demonstrated in liver homogenates during the early phase of liver regeneration (2). Extracts of Ginkgo biloba leaves contain approximately 300 chemicals. While the precise role of each component remains unclear, studies have shown that flavonoids and terpenoids are the most effective components in the EGb761 extract. The standardized formulation of G. biloba extract comprises approximately $24 \%$ of flavonoid glycosides (primarily quercetin, kaempferol, and isorhamnetin) and $6 \%$ of terpene lactones (2.8\%-3.4\% of ginkgolides A, B, and C and $2.6 \%$ $3.2 \%$ of bilobalide) (3). EGb761 is known for its antioxidant properties due to its ability to scavenge free radicals and neutralize ferryl ion-induced peroxidation (4). It can antagonize platelet-activating factor in rats (5). The administration of EGb761 increases arterial and capillary blood flow in ischemic vascular disease. Particularly, terpenoids and flavonoids from EGb761 possess vasorelaxant properties. Furthermore, EGb761 enhances nerve regeneration in the central and peripheral nerve

\footnotetext{
Address for Correspondence: Dr. Nahide Ekici Günay, Department of Clinical Biochemistry, University of Health Sciences, Training and Research Hospital, Kayseri, Turkey e-mail: edihan30@yahoo.comＯRCID ID: orcid.org/0000-0002-3041-7427

Received: 2 February 2017 Accepted: 10 December 2017 • DOI: 10.4274/balkanmedj.2016.1830

Available at www.balkanmedicaljournal.org

Cite this article as:

Ekici Günay N. Administration of Ginkgo biloba Extract (EGb761) Alone and in Combination with FK506 Promotes Liver Regeneration in a Rat Model of Partial Hepatectomy. Balkan Med J 2018;35:174-80

${ }^{\circ}$ Copyright 2018 by Trakya University Faculty of Medicine / The Balkan Medical Journal published by Galenos Publishing House.
} 
systems (6). On the other hand, FK506 (tacrolimus), which has been widely used as an immunosuppressant, is a potent calcineurin inhibitor that weakens the effects of cytokines, thereby stimulating hepatocyte proliferation following partial hepatectomy (7). Recently, herbal medications have been increasingly considered as an effective and safe reinforcement to synthetic drugs. However, there is a lack of approval for these herbal medications due to inadequate research conducted using experimental liver regeneration models. Therefore, in this study, we investigated whether EGb761, with and without FK506, promotes liver regeneration in a rat model for partial hepatectomy.

\section{MATERIALS AND METHODS}

The experimental protocol was approved by the animal research ethics committee of Erciyes University, Kayseri, Turkey (Approval no: 2004-a18).

\section{Chemicals}

Reduced glutathione, NADH disodium salt, nitrobluetetrazolium, phenazine methosulphate, thiobarbituric acid, p-nitrophenyl phosphate, trichloroacetic acid, chloroform, sodium pyrophosphate, Triton X-100, hydrogen peroxide, and methanol were procured from Merck Specialties and Sigma-Aldrich Chemicals (St. Louis, MO). Solvents used for thin layer chromatography, extraction, and estimation of oxidative stress were of analytical grade. FK506 monohydrate was purchased form Astellas Pharma US Inc. (Tokyo, Japan) and EGb761 from Sigma-Aldrich (Catalog number NIST SRM 3246). Thymidine kinase activity was radioimmunologically measured using the Prolifigen ${ }^{\circledR}$ thymidine kinase (TK)-radioenzymatic assay (REA) commercial kit (Sangtec Medical, Sweden).

\section{Rats and treatments}

Male Wistar albino rats aged 12 weeks and weighing 300-400 $\mathrm{g}$ were supplied by the Animal Experimental Center of Erciyes University (Turkey). The rats were kept under controlled conditions of temperature $\left(22-24{ }^{\circ} \mathrm{C}\right)$ and humidity $(40 \% \pm 10 \%)$ with a $12 \mathrm{~h}$ light/dark cycle. The rats had access to commercial rodent food and water ad libitum. All procedures involving animals were conducted in strict accordance with the Turkish legislation on the use and care of laboratory animals and guidelines established by the Institute for Experimental Animals of Erciyes University (Turkey). A total of 75 rats were divided into five groups: the sham group underwent excision of only the hepatic suspensory ligament, whereas the control $(5 \mathrm{~mL} / \mathrm{kg}$ of $0.9 \% \mathrm{NaCl}$ ), EGb761, FK506, and EGb761 + FK506 groups underwent hepatectomy. EGb761 (25 mg/kg, i.p.), FK506 monohydrate $(1 \mathrm{mg} / \mathrm{kg}$, i.p.), and combination of these drugs were administered once daily for three consecutive days to the rat medicament groups. After 3 days, the rats underwent $70 \%$ hepatectomy according to the Anderson and Higgins technique based on the calculation of liver regeneration volume using the Child's formula. Partial hepatectomy was performed under anesthesia (10/90 mg/kg xylazine/ketamine i.p.) as previously reported (8). A resection of $70 \%$ was selected because it is the critical limit for liver failure (9).

\section{Biochemical measurements}

The rats were killed $48 \mathrm{~h}$ after hepatectomy, and blood samples were collected from the hepatic veins. The protein content in the liver homogenate was analyzed according to the method of Lowry et al. (10). Bovine serum albumin (BSA) $(1 \mathrm{mg} / \mathrm{mL})$ was used as a standard. The protein content in the samples was estimated from a standard curve obtained using different BSA concentrations. The activities of aspartate aminotransferase (AST), alanine aminotransferase (ALT), and gamma glutamyl transferase (GGT), alkaline phosphatase (ALP) and lipid profiles were assayed using a Konelab 60i automatic analyzer (Thermo Fisher Scientific, Finland).

\section{Calculation of the liver regeneration index}

The excised wet liver weight was recorded at the time of hepatectomy. The liver weight as a percentage of the body weight was expressed as a relative liver weight (RLW) to compare the rates of liver regeneration between the groups. To calculate RLW, the residual liver weight after partial hepatectomy was subtracted from the liver weight measured at the time of sacrifice. Then, a ratio of this value to the total liver weight [accepted as $3.5 \%$ of the rat body weight (11)] was calculated and multiplied by 100 to yield the liver regeneration rate. The liver regeneration rate was calculated according to the Child's formula (Equation 1) (12).

Equation 1. Liver regeneration rate's (equation 1) expression by words math application;

Regeneration rate $(\%)=\frac{\text { Liver weight of sacrificed rat }-(\text { total liver weight }- \text { resected liver weight })}{\text { Extracted liver weight }} \times 100$

The results are expressed as percentages. The remaining liver which included regenerated tissue and blood specimens collected from surviving and sacrificed rats $(n=51)$ after $18 \mathrm{~h}$ were placed in tubes and stored at $-80{ }^{\circ} \mathrm{C}$ until further use.

\section{Oxidative stress estimation}

Antioxidant activity was evaluated in the liver tissue and serum. To calculate antioxidant activity in liver samples, tissues were collected in screw-capped polypropylene vials and homogenized in ice-cold 0.1 M Pharmaceutical Benefits 
Scheme (PBS) (pH 7.4) at a ratio of 10:1 (100 $\mathrm{mg}$ of tissue in $1 \mathrm{~mL}$ of PBS). After centrifugation at $10.000 \mathrm{rpm}$ for $30 \mathrm{~min}$ at $4{ }^{\circ} \mathrm{C}$, the supernatant was collected. To assess oxidative stress, activities of thiobarbituric acid reactive substances were measured using the method described by Okhawa et al. (13). The results are expressed as $\mathrm{nmol} / \mathrm{mL}$ of malondialdehyde (MDA) production per gram of the wet tissue. Myeloperoxidase enzyme activity was estimated using the method described by Bradley et al. (14), and the increase in absorbance at $460 \mathrm{~nm}$ was measured using spectrophotometry. The superoxide dismutase (SOD) (15), glutathione peroxidase (16), and glutathione reductase assays were performed using the methods previously described (17).

\section{Histopathological examination}

Regenerated liver tissue specimens were fixed in formaldehyde and stained with hematoxylin-eosin. The ratio of the number of hepatocytes undergoing mitosis to the total number of hepatocytes was reported as the mitotic index (MI).

\section{Statistical analysis}

All numerical data are reported as the mean \pm standard deviation. Statistical analysis was performed using the SPSS 22.0 software for Windows. The assumption of normality was checked using the Kolmogoro-Smirnov test. Group comparisons were analyzed using ANOVA, and pair-wise comparisons were performed using the Scheffe post-hoc test. Statistical significance was defined as $p<0.05$.

\section{RESULTS}

In the present study, the liver regeneration ratio, MI, extent of liver damage, and oxidative stress marker levels were investigated after the administration of EGb761 in a rat hepatectomy model. For this purpose, the effect of EGb761 was compared with that of the immunosuppressant FK506, which is widely used and has a well-known regenerative effect on the liver. None of the rats died during the course of drug administration prior to hepatectomy. In the period between hepatectomy and sacrifice, 22 rats died (three in the sham, five in the control, four in the EGb761, five in the FK506, and five in the EGb761 + FK506 groups) and were excluded from the study. The liver regeneration parameters (thymidine kinase, regeneration rate, mitotic index) and antioxidant enzyme levels (glutathione reductase, myeloperoxidase, MDA levels) were showed to be significant differences among the sham, control, FK506 and EGb761 + FK506 groups $(\mathrm{p}<0.05)$. Moreover, the EGb761 group had higher liver regeneration rate and MI than those in the FK506 and EGb761 + FK506 groups. The liver weights, regeneration rates, and mitotic indices of the groups are shown in Table 1 and Figures 1-4, respectively. The EGb761 group showed higher levels of ALT and AST than the sham group $(\mathrm{p}<0.05)$. However, there were no significant differences in these levels among the four groups that underwent hepatectomy. The EGb761, FK506, and EGb761 + FK506 groups had significantly higher serum ALP levels than those in the control and sham groups $(\mathrm{p}<0.05)$, although the increase in the EGb761 group was not as high as in the other drug treatment groups. There was no significant difference among the groups in terms of GGT levels. The serum parameters are summarized in Table 2.

There were significant differences between the groups in terms of thymidine kinase levels, with highest levels in the EGb761 and FK506 groups, followed by the EGb761 + FK506 group $(\mathrm{p}<0.05)$ (Table 3). The mitotic indices of the EGb761 and FK506 groups were significantly higher than those of the control and sham groups $(p<0.001)$. Liver histology slides are shown in Figures 4a-4e. The antioxidant enzyme levels are summarized in Table 4. The SOD levels did not differ between the groups, whereas MDA levels in tissue samples were significantly lower in the EGb761 + FK506 group than in the FK506 group. Additionally, MDA levels were significantly lower in the EGb761 group than in the FK506 group. The correlations were studied in each rat group. There was a positive correlation between thymidine kinase with triglyceride $(\mathrm{r}=0.78, \mathrm{p}<0.05)$ and liver regeneration rate $(r=0.73, p<0.05)$. In the $E G b 761+$

TABLE 1. Liver weights of rats

\begin{tabular}{|c|c|c|c|c|c|c|}
\hline Parameters (g) & $\begin{array}{c}\text { Sham }(\mathrm{n}=10) \\
\mathrm{X} \pm \mathrm{SD}\end{array}$ & $\begin{array}{c}\text { Control (n=11); } \\
\mathrm{X} \pm \mathrm{SD}\end{array}$ & $\begin{array}{c}\mathrm{EGb} 761(\mathrm{n}=11) \\
\mathrm{X} \pm \mathrm{SD}\end{array}$ & $\begin{array}{c}\text { FK506 }(\mathrm{n}=10) \\
\mathrm{X} \pm \mathrm{SD}\end{array}$ & $\begin{array}{c}\mathrm{EGb} 761+\mathrm{FK} 506(\mathrm{n}=11) \\
\mathrm{X} \pm \mathrm{SD}\end{array}$ & $\mathrm{p}$ \\
\hline Rat weight (g) & $322.7 \pm 36.7$ & $366.8 \pm 37.0$ & $344.2 \pm 34.8$ & $342.9 \pm 38.5$ & $337.6 \pm 39.37$ & 0.196 \\
\hline Resected liver weight (g) & - & $7.9 \pm 1.1$ & $8.1 \pm 1.3$ & $7.1 \pm 0.9$ & $7.6 \pm 0.4$ & 0.086 \\
\hline Estimated total liver weight (g) & - & $11.6 \pm 1.1$ & $11.7 \pm 1.1$ & $11.6 \pm 1.3$ & $11.4 \pm 1.3$ & 0.197 \\
\hline $\begin{array}{l}\text { Total liver weight after sacrificing the } \\
\text { rats }(\mathrm{g})\end{array}$ & $6.4 \pm 1.1^{\mathrm{b}}$ & $4.7 \pm 0.6^{\mathrm{ac}}$ & $7.1 \pm 1.2^{b}$ & $5.5 \pm 0.8$ & $5.5 \pm 0.9$ & $<0.001^{*}$ \\
\hline
\end{tabular}




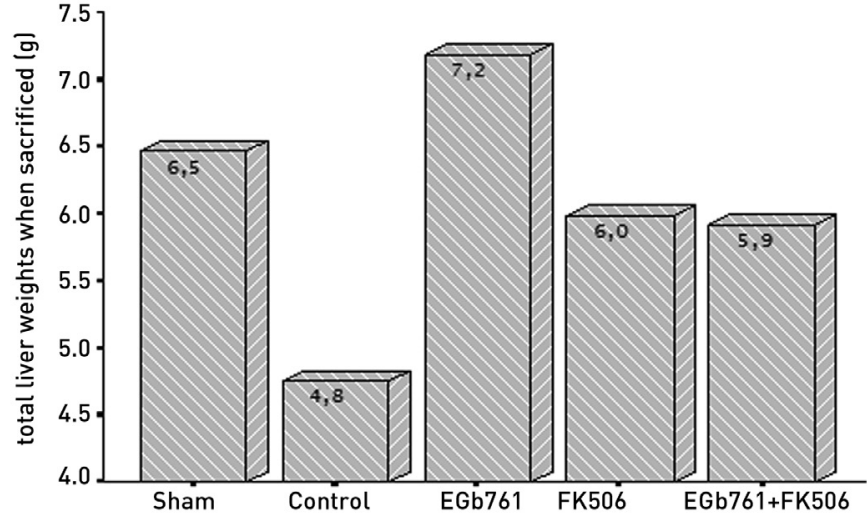

FIG. 1. Total liver weights of sacrificed rats according to study groups.

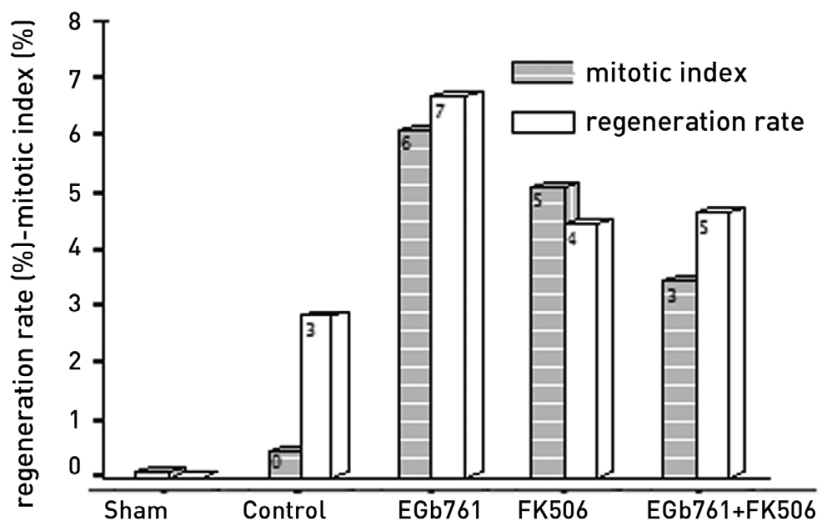

FIG. 2. Graph of regeneration rate and mitotic index according to study groups.

TABLE 2. Biochemical parameters of rats

\begin{tabular}{|c|c|c|c|c|c|c|}
\hline Parameters & Sham $(n=10)$ & Control (n=11) & $\mathrm{EGb} 761(\mathrm{n}=11)$ & FK506 $(n=10)$ & EGb761 + FK506 $(n=11)$ & $\mathrm{p}$ \\
\hline Total bilirubin (mg/dL) & $0.4 \pm 0.1$ & $0.5 \pm 0.1$ & $1.3 \pm 1.9$ & $1.7 \pm 2.5$ & $1.8 \pm 1.8$ & 0.169 \\
\hline Direct bilirubin (mg/dL) & $0.5 \pm 0.1$ & $0.6 \pm 0.5$ & $1.1 \pm 1.6$ & $1.5 \pm 2.3$ & $1.6 \pm 1.6$ & 0.198 \\
\hline AST (U/L) & $78.6 \pm 13.3^{\text {bcde }}$ & $348.8 \pm 174.7^{\mathrm{a}}$ & $811.7 \pm 792.2^{\mathrm{a}}$ & $612.1 \pm 342.5^{\mathrm{a}}$ & $775.9 \pm 605.7^{\mathrm{a}}$ & $0.004 *$ \\
\hline GGT (U/L) & $19.2 \pm 3.2$ & $21.9 \pm 17.7$ & $21.5 \pm 21.1$ & $12.5 \pm 4.5$ & $12.9 \pm 8.7$ & 0.286 \\
\hline $\operatorname{ALP}(\mathrm{U} / \mathrm{L})$ & $154 \pm 27^{b}$ & $292.1 \pm 138.3^{\text {acde }}$ & $929.8 \pm 567.5^{\mathrm{ab}}$ & $966 \pm 627.5^{\mathrm{ab}}$ & $974.5 \pm 460.3^{\mathrm{ab}}$ & $<0.001^{*}$ \\
\hline Total protein $(\mathrm{g} / \mathrm{dL})$ & $7.0 \pm 0.2^{\text {bcde }}$ & $6.3 \pm 0.3$ acde & $5.3 \pm 0.3^{\mathrm{ab}}$ & $5.3 \pm 0.3^{\mathrm{ab}}$ & $5.4 \pm 0.3^{\mathrm{ab}}$ & $<0.001^{*}$ \\
\hline Uric acid (mg/dL) & $1.6 \pm 0.5^{\mathrm{de}}$ & $1.9 \pm 0.3^{\text {cde }}$ & $1.2 \pm 0.2^{\mathrm{b}}$ & $0.7 \pm 0.3^{\mathrm{ab}}$ & $0.9 \pm 0.2^{\mathrm{ab}}$ & $<0.001 *$ \\
\hline Triglyceride (mg/dL) & $89 \pm 25^{b}$ & $49.0 \pm 13.25^{\mathrm{ac}}$ & $78.1 \pm 12.0^{\mathrm{b}}$ & $66.1 \pm 15.7$ & $70.4 \pm 22.3$ & $<0.001 *$ \\
\hline Cholesterol (mg/dL) & $128 \pm 26^{\text {bcde }}$ & $48.8 \pm 14.7$ ace & $85.0 \pm 18.5^{\mathrm{ab}}$ & $77.5 \pm 22.7^{\mathrm{a}}$ & $71.0 \pm 21.1^{\mathrm{a}}$ & $<0.001^{*}$ \\
\hline $\mathrm{HDL}(\mathrm{mg} / \mathrm{dL})$ & $107.1 \pm 23.8^{\text {bcde }}$ & $25.4 \pm 9.2^{\mathrm{a}}$ & $35.0 \pm 10.9^{\mathrm{a}}$ & $25.6 \pm 15.0^{\mathrm{a}}$ & $30.7 \pm 20.4^{a}$ & $<0.001 *$ \\
\hline
\end{tabular}

Data are reported as the mean \pm standard deviation. Based on Scheffe procedure; agroups which differ from the sham group; b $_{\text {groups }}$ which differ from the control group; ${ }^{\mathrm{c}}$ groups which differ from the EGb761 group; dgroups which differ from the FK506 group; and egroups which differ from the EGb761 + FK506 group. ALT: aspartate aminotransferase; AST: alanine aminotransferase; GGT: gamma glutamyl transferase; ALP: alkaline phosphatase; HDL: high-density lipoprotein; LDL: low-density lipoprotein; LDH: lactate dehydrogenase

\begin{tabular}{|c|c|c|c|c|c|c|}
\hline Parameters & Sham $(n=10)$ & Control (n=11) & EGb761 $(n=11)$ & FK506 $(n=10)$ & EGb761 + FK506 $(n=11)$ & $\mathrm{p}$ \\
\hline Thymidine kinase (U/L) & $4.6 \pm 1.0^{\mathrm{cd}}$ & $6.2 \pm 3.3^{\mathrm{cd}}$ & $9.5 \pm 4.08^{\mathrm{ab}}$ & $9.8 \pm 2.9$ abe & $5.4 \pm 3.13^{\mathrm{d}}$ & $<0.001^{*}$ \\
\hline Regeneration rate (\%) & - & $2.9 \pm 0.1^{\mathrm{ce}}$ & $6.6 \pm 1.3^{\text {bde }}$ & $4.4 \pm 1.7 \mathrm{c}$ & $4.6 \pm 1.6^{\mathrm{bc}}$ & $<0.001^{*}$ \\
\hline Mitotic index (\%) & $0.1 \pm 0.1^{\mathrm{cd}}$ & $0.4 \pm 0.8^{\mathrm{cd}}$ & $6.1 \pm 5.4^{\mathrm{ab}}$ & $5.2 \pm 4.0^{\mathrm{ab}}$ & $3.4 \pm 2.2$ & $<0.001^{*}$ \\
\hline
\end{tabular}

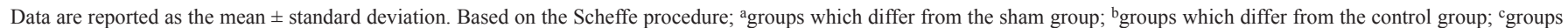

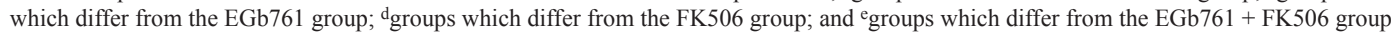

TABLE 4. Antioxidant enzyme levels in rats

\begin{tabular}{|c|c|c|c|c|c|c|}
\hline Parameters & Sham $(n=10)$ & Control $(\mathrm{n}=11)$ & EGb761 $(n=11)$ & FK506 $(n=10)$ & EGb761 + FK506 $(n=11)$ & $\mathrm{p}$ \\
\hline Superoxide dismutase (U/g Hb) & $3002 \pm 328$ & $3450.1 \pm 901$ & $3791 \pm 1242$ & $3435 \pm 2068$ & $3535 \pm 788$ & 0.693 \\
\hline Glutathione reductase $(\mathrm{mmol} / \mathrm{L})$ & $5.2 \pm 1.1^{\mathrm{d}}$ & $8.6 \pm 4.8$ & $8.3 \pm 1.5$ & $10.3 \pm 3.7^{\mathrm{a}}$ & $6.3 \pm 1.9$ & $0.03 *$ \\
\hline Glutathione peroxidase (U/L) & $7.8 \pm 0.8$ & $9.7 \pm 2.3$ & $9.2 \pm 5.7$ & $11.13 \pm 3.6$ & $11.13 \pm 3.1$ & 0.194 \\
\hline Myeloperoxidase tissue (U/L) & $9.4 \pm 2.7^{\mathrm{be}}$ & $40.6 \pm 13.8^{\mathrm{ac}}$ & $18.01 \pm 7.8^{\mathrm{be}}$ & $23.43 \pm 14.0^{\mathrm{e}}$ & $51.59 \pm 17.4^{\mathrm{acd}}$ & $<0.001^{*}$ \\
\hline Myeloperoxidase plasma (U/L) & $43.57 \pm 2.1^{\text {cde }}$ & $110.4 \pm 48.5$ & $121.7 \pm 60.5^{\mathrm{a}}$ & $124.6 \pm 0.2^{\mathrm{a}}$ & $117.0 \pm 53.6^{\mathrm{a}}$ & $<0.005^{*}$ \\
\hline $\operatorname{MDA}(\mathrm{mmol} / \mathrm{L})$ & $2.1 \pm 0.6^{\text {bcde }}$ & $5.7 \pm 1.4^{\mathrm{ad}}$ & $6.3 \pm 1.5^{\mathrm{ad}}$ & $9.3 \pm 3.8^{\text {abce }}$ & $5.7 \pm 1.2^{\mathrm{ad}}$ & $<0.001^{*}$ \\
\hline
\end{tabular}

Data are reported as the mean \pm standard deviation. Based on the Scheffe procedure; ${ }^{a}$ groups which differ from the sham group; ${ }^{\text {groups }}$ which differ from the control group; ${ }^{\text {groups }}$

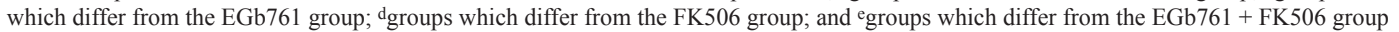


FK506 group, there was a negative correlation between the plasma MPO level and liver regeneration rate $(\mathrm{r}=-0.81$, $\mathrm{p}<0.05$ ) (Figure 3).

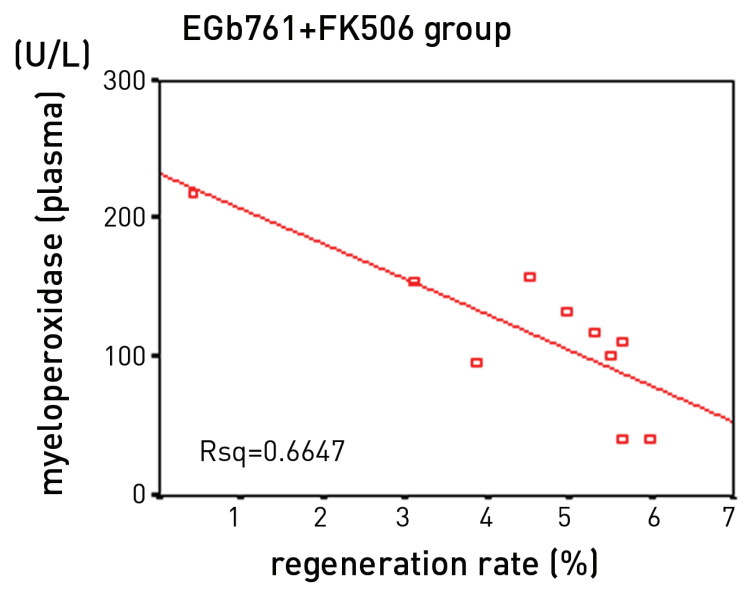

FIG. 3. Myeloperoxidase and regeneration rate correlation curve.

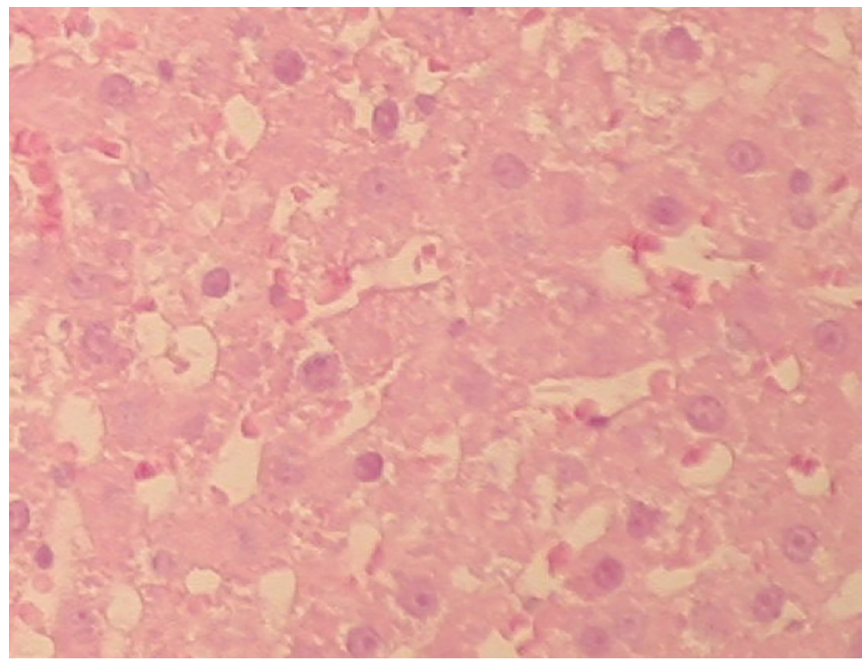

FIG. 4a. Photomicrograph of liver sections of sham group rat $48 \mathrm{~h}$ after a $70 \%$ partial hepatectomy. Note the absance of mitotic figures in the hepatocytes (H\&E x20)

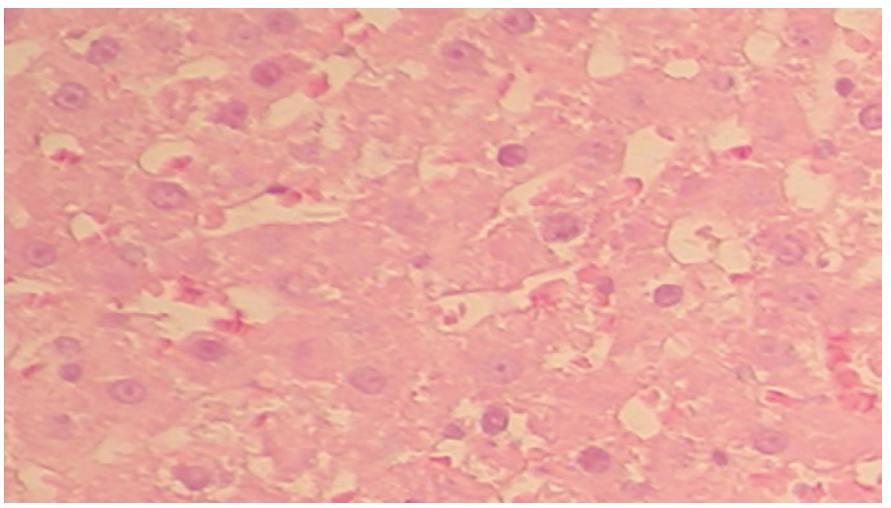

FIG. 4b. Photomicrograph of liver sections of control hepatectomy group rat $48 \mathrm{~h}$ after a $70 \%$ partial hepatectomy. Note the absance of mitotic figures in the hepatocytes (H\&E X20).

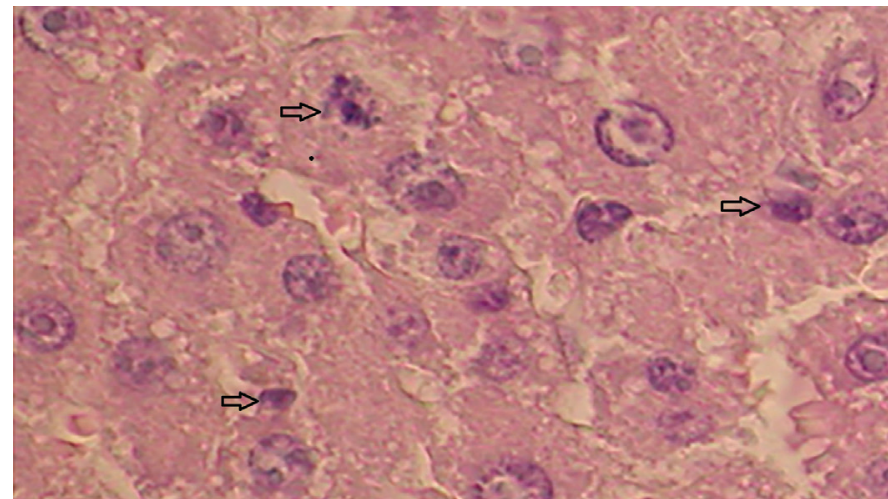

FIG. 4c. Photomicrograph of liver sections of FK506 group rat after $48 \mathrm{~h}$ a $70 \%$ partial hepatectomy. The arrows denote multiple mitotic figures in the hepatocytes (H\&E x20).

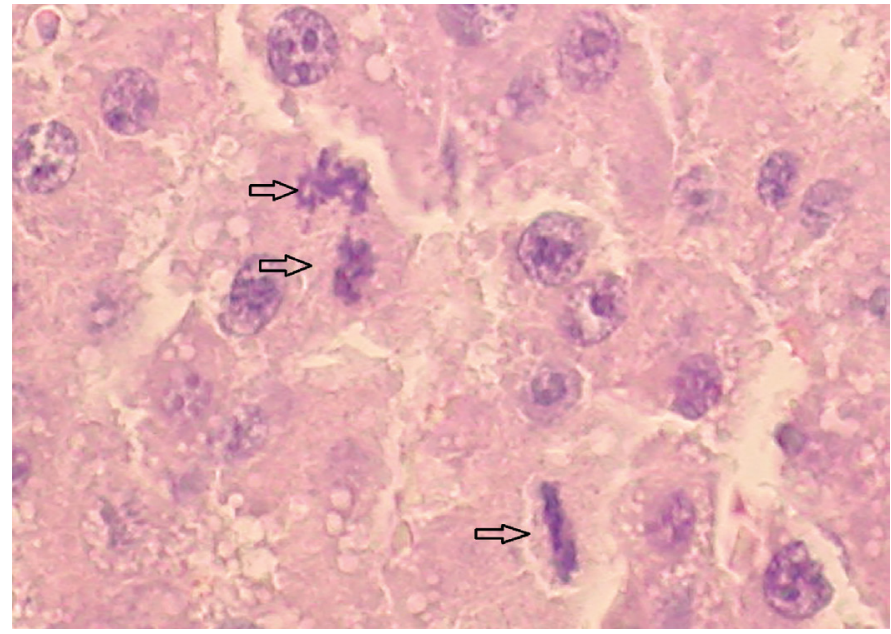

FIG. 4d. Photomicrograph of EGb761 group rat's liver sections after 48 h a $70 \%$ partial hepatectomy. The arrows denote multiple mitotic figures. Note intensive nuclear enlargement in the hepatocytes (H\&E x20).

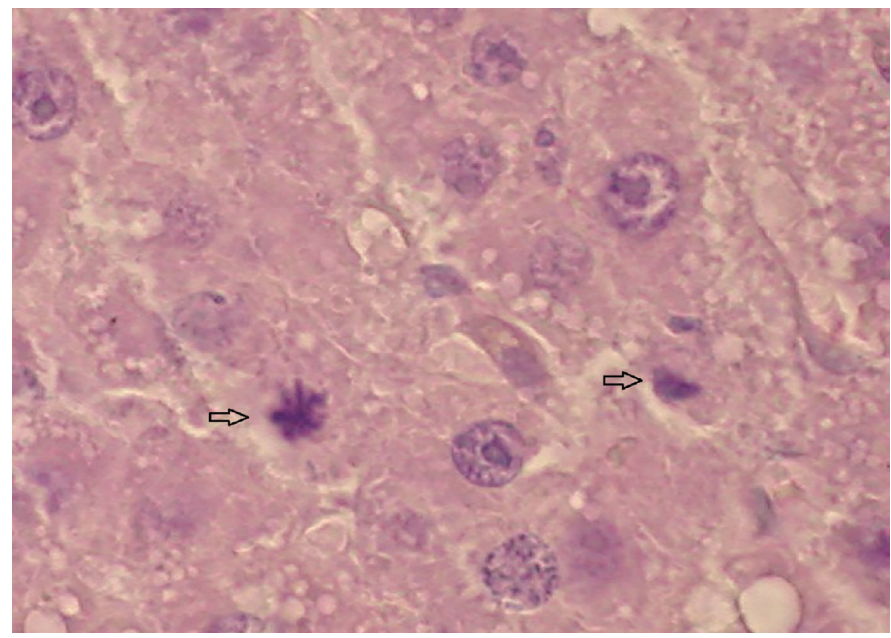

FIG. 4e. Photomicrograph of liver sections of drug combination group (EGb761 + FK506) rat after $48 \mathrm{~h}$ a $70 \%$ partial hepatectomy. The arrows denote mitotic figures in hepatocytes (H\&E x20) group. 


\section{DISCUSSION}

Regeneration is a vital process, which is expected to occur after partial hepatectomy and liver transplantation. The present study revealed that the administration of $25 \mathrm{mg} / \mathrm{kg}$ of EGb761 alone or in combination with FK506 increased the liver regeneration rate, $\mathrm{MI}$, and regenerated liver mass in a rat partial hepatectomy model.

The hepatic regenerative process in rats begins with an increase in the levels of various signaling molecules from the third hour after hepatectomy, peaks within 2-3 days, and ends at 5-7 days when the remnant lobe enlarges to the size of the original liver (18). In a similar study of rat liver regeneration after partial hepatectomy, it was shown that maximum liver regeneration at 36 and $48 \mathrm{~h}$ was significantly higher, even when only one drug dose (ICI 182,780) was administered 24 h before hepatectomy (19). In another rat study, orthotropic liver transplantation was performed after partial hepatectomy, with EGb761 intravenously administered $1 \mathrm{~h}$ prior to surgery, resulting in alleviation of hepatic inflammation/necrosis between 2 and 24 h postoperatively (20). In our study, the rats were sacrificed at the $48^{\text {th }}$ hours when the liver regeneration rate was expected to be the maximum. The actual and expected regeneration rates in our study were consistent for all three drug doses. Flavonoids are extensively metabolized following oral administration and undergo metabolic transformation, such as methylation, sulfation, and glucuronidation, thereby changing their structures and biological activities. Oral administration of EGb761 may have a prolonged effect (up to 8 weeks), and doses up to $100 \mathrm{mg} / \mathrm{kg}$ have been used for various chronic and degenerative diseases, such as cancers and cardiovascular diseases, in both in vitro and in vivo study models (21). EGb761 has a broad range of therapeutic effects, and low doses have also yielded beneficial effects in some experimental models. In animal trials, the pharmacological activity of EGb761 was found to be significantly better with intraperitoneal administration than with oral administration, even at low (10 $\mathrm{mg} / \mathrm{g}$ ) doses for neurological recovery (22). Therefore, we used the intraperitoneal administration route in our study due to its effective pharmacological effect. Severe liver damage can occur in many cases, such as ischemia, followed by reperfusion, resection, and transplantation. The methods of reducing the damage caused by ischemia-reperfusion in the liver have been studied. FK506 is known to be an immunosuppressant that ameliorates hepatic damage due to ischemia and reperfusion in rats (23). The inactivation of free radicals, which are mainly responsible for tissue damage, reduces inflammation and accelerates the regenerative process (24). In this context, we used EGb761 along with the free radical scavenger FK506. We aimed to investigate the use of an antioxidant along with an immunosuppressant, such as FK506. One of the main results of our study was that EGb761, by reducing tissue oxidative stress, positively contributed to the regeneration process. We could not find studies on the effectivity of EGb761 alone or in combination with FK506 on liver injury in a rat hepatectomy model. The combination of EGb761 and FK506 had a considerable effect on the liver regeneration rate. Furthermore, EGb761, when used alone, showed a regenerative effect, which was similar to that of FK506. This indicated that the effect of EGb761 and FK506 in stimulating liver regeneration was synergistic. Drugs with different mechanisms may be more effective for this purpose when used together. These results are consistent with those of a previous report which stated that the administration of EGb761 promoted peripheral nerve regeneration and neovascularization in rats (25). Although all the groups showed higher results than those of the sham group, EGb761 and FK506 administration did not affect AST and ALT levels in the hepatectomy model. The lack of difference between the groups in terms of GGT levels can be explained by the fact that GGT, which can be induced by some drugs, is unaffected by EGb761. FK506 has been reported to increase ALP levels in osteoblasts with proliferative effects (26), but we could not find a similar study on EGb761. It is known that ALP levels are elevated during liver regeneration (27). Because the control group also underwent hepatectomy, we could not associate elevated ALP levels (an average increase of $216 \%$ in all the groups) with hepatectomy. Therefore, elevated ALP levels were attributed to FK506 and EGb761 administration. The evaluation of ALP levels after FK506 or EGb761 administration, either alone or in combination, can be used for reflecting the positive proliferative effect of these drugs on the liver cells in the regeneration process. Some studies have indicated that the levels of SOD, an antioxidant enzyme, are low after partial hepatectomy, although others have not found such an effect. When EGb761 was used in rats with liver fibrosis induced by intraperitoneal injection of carbon tetrachloride, there was an increase in the SOD levels (28); however, we did not observe a significant increase in the SOD levels in our model. Furthermore, we did not find any other study in which the association between EGb761 and SOD levels was investigated using the same model. After hepatectomy, free radicals generated as a result of lipid peroxidation on the hepatic cell membrane cause tissue damage. The best way to assess lipid peroxidation is to measure MDA levels (2). According to our findings, combined administration of FK506 and EGb761 had a synergistic effect, resulting in significantly lower MDA levels $(\mathrm{p}<0.001)$. Thymidine kinase can be measured in the blood of hepatectomized rats, providing a noninvasive assessment of liver regeneration (29). We found that thymidine kinase levels in the EGb761 and FK506 groups 
were significantly higher than in the control and sham groups $(p<0.001)$, with similar results for the regeneration rate $(\%)$ and MI $(\mathrm{p}<0.001)$. However, we did not find any study on the association between thymidine kinase levels, regeneration rate, and MI as measures of liver regeneration after EGb761 and FK506 administration, either alone or in combination with each other, in a rat partial hepatectomy model. Therefore, we could not perform a comprehensive comparison between the results obtained in our study and those in other studies in terms of the effect of EGb761 in a rat hepatectomy model.

We showed that EGb761 administration before hepatectomy in rats reduces the extent of tissue damage caused by free radicals and inflammation. EGb761 administration also induces liver regeneration by reducing the extent of liver damage through its antioxidative and anti-inflammatory effects in a rat hepatectomy model. Further clinical examinations are necessary, and detailed experiments should be performed for the use of EGb761 in the treatment of patients after hepatectomy and liver transplantation.

Financial Disclosure: All expenses for the study were covered by the authors. Conflict of Interest: No conflict of interest was declared by the authors.

\section{REFERENCES}

1. Miyahara S, Yokomuro K, Takahashi H, Kimura Y. Regeneration and the immune system. I. In vitro and in vivo activation of lymphocytes by liver regeneration and the role of Kupffer cells in stimulation. Eur J Immunol 1983;13:878-83.

2. Guerrieri F, Vendemiale G, Grattagliano I, Cocco T, Pellecchia G, Altomare E. Mitochondrial oxidative alterations following partial hepatectomy. Free Radic Biol Med 1999:26;34-41.

3. Nash K, Shah ZA. Current perspectives on the beneficial role of Ginkgo biloba in neurological and cerebrovascular disorders. Integr Med Insights 2015;10:1-9.

4. Bridi R, Crossetti FP, Steffen VM, Henriques AT. The antioxidant activity of standardized extract of Ginkgo biloba (EGb 761) in rats. Phytother Res 2001;15:449-51.

5. Koch E. Inhibition of platelet activating factor (PAF)-induced aggregation of human thrombocytes by ginkgolides: considerations on possible bleeding complications afte oral intake of Ginkgo biloba extracts. Phytomedicine 2005;12:10-6.

6. Yoo DY, Nam Y, Kim W, Yoo KY, Park J, Lee CH, et al. Effects of Ginkgo bilob extract on promotion of neurogenesis in the hippocampal dentate gyrus in C57BL/6 mice. J Vet Med Sci 2011;73:71-6.

7. Backes AN, Tannuri AC, Backes FN, Queiroz AJ, Coelho MC, da Silva EL, et al. Effects of tacrolimus and insulin in a liver regeneration model in growing animals with portal vein stenosis: immunohistochemical and molecular studies. Pediatr Surg Int 2014;30:423-9.

8. Ohtake M, Sakaguchi T, Yoshida K, Muto T. Hepatic branch vagotomy can suppress liver regeneration in partially hepatectomized rats. HPB Surg 1993;6:277-86.

9. Emond J, Capron-Laudereau M, Meriggi F, Bernuau J, Reynes M, Houssin D. Extent of hepatectomy in therat. Evaluation of basal conditions and effect of therapy. Eur Surg Res 1989;21:251-9.
10. Lowry OH, Rosebrough NJ, Farr AL, Randall RJ. Protein measurement with the folin phenol reagent. J Biol Chem 1951;193,265-74

11. Kagure K, Zhang YQ, Shibata H, Kojima I. Immediate onset of DNA synthesis in remnant rat liver after $90 \%$ hepatectomy by an administration of follistatin. J Hepatol 1998;28:977-84

12. Fishback FC. A morphologic study of regeneration of the liver after partial removal. Arch Pathol 1929;7:956-77.

13. Okhawa H, Ohishi N, Yagi K. Assay for lipid peroxides in animal tissue by Thiobarbituric acid reaction. Anal Biochem 1979;95:351-8.

14. Bradley PP, Priebat DA, Christensen RD, Rothstein G. Measurement of cutaneous inflamation. Estimation of neutrophil content with an enzyme marker. J Invest Dermatol 1982;78:206-9.

15. Beauchamp C, Fridovich I. Superoxide dismutase improved assays and an assay applicable to acrilamide gels. Anal Biochem 1971:44;276-87.

16. Paglia DE, Valentine WN. Studies on the quantitative and qualitative characterization of erythrocyte glutathione peroxidase. J Lab Clin Med 1967;70:158-69.

17. Goldberg DM, Spooner RJ. "Glutathione Reductase," In: Bermeyer HU, Bergmeye J, GraBI M, editors. Methods of Enzymatic Analysis, 3rd Edition, Verlag Chemie: Weinheim; 1983:258-65

18. Wang G, Zhao C, Chen S, Li X, Zhang L, Chang C, et al. A preliminary in vivo study of the effects of OPN on rat liver regeneration induced by partial hepatectomy. Mol Biol Rep 2016;43:1371-82.

19. Batmunkh B, Choijookhuu N, Srisowanna N, Byambatsogt, Synn Oo P, Noor Ali M, et al. Estrogen accelerates cell proliferation through estrogen receptor $\alpha$ during rat liver regeneration after partial hepatectomy. Acta Histochem Cytochem 2017;50:3948

20. Zhou JB, Yang XK, Ye QF, Ming YZ, Xia ZJ. Effect of extract of ginkgo biloba leaves on theprecondition of liver graft in rat liver transplantation. Zhong Nan Da Xue Xue Bao Yi Xue Ban 2007;32:54-8.

21. Yoshikawa T. Food Factors for Health Promotion. In: Wang Y, Ho CT, editors Metabolism of Flavonoids. Kyoto: Basel Karger; 2009:64-74.

22. Tighilet B, Lacour M. Pharmacological activity of the Ginkgo biloba extract (EGb 761 ) on equilibrium function recovery in the unilateral vestibular neurectomized cat. J Vestib Res 1995;5:187-200.

23. Sakr MF, Zetti GM, Hassanein TI, Farghali H, Nalesnik MA, Gavaler JS, et al. FK 506 ameliorates the hepatic injury associated with ischemia and reperfusion in rats. Hepatology 1991;13:947-51.

24. Griffiths EJ, Halestrap AP. Protection by cyclosporin a of ischemic/reperfusioninduced damage in isolated rat hearts. J Mol Cell Cardiol 1993;25:1461-9.

25. Zhu Z, Zhou X, He B, Dai T, Zheng C, Yang C, et al. Ginkgo Biloba Extract (EGb 761) Promotes peripheral nerve regeneration and neovascularization after acellular nerve allografts in a rat model. Cell Mol Neurobiol 2015;35:273-82.

26. Field FJ, Mathur SN, LaBrecque DR. Cholesterol metabolism in regenerating liver of the rat. Am J Physiol 1985;249:679-84.

27. O'Brien PJ, Slaughter MR, Polley SR, Kramer K. Advantages of glutamate dehydrogenase as a blood biomarker of acute hepatic injury in rats. Lab Anim 2002;36:313-21

28. Liu SQ, Yu JP, Chen HL, Luo HS, Chen SM, Yu HG. Therapeutic effects and molecular mechanisms of Ginkgo biloba extract on liver fibrosis in rats. Am J Chin Med 2006;34:99-114.

29. Moreno D, Neri L, Vicente E, Vales A, Aldabe R. Use of thymidine kinase recombinan adenovirus and ganciclovir mediated mouse liver preconditioning for hepatocyte xenotransplantation. Methods Mol Biol 2017;1506:179-92. 